Journal of Health Science
(Jurnal Ilmu Kesehatan)

\title{
Peran Keluarga Terhadap Fungsi Kognitif Lansia Di Desa Pandian Kabupaten Sumenep
}

\author{
Rika Oktaviana', Syaifurrahman Hidayat ${ }^{2}$, Elyk Dwi Mumpuningtias ${ }^{3}$ \\ Program Studi Keperawatan Universitas Wiraraja, sumenep, Indonesia \\ 'oktavianarika05@gmail.com, 2dayat.fik@wiraraja.ac.id, ${ }^{3}$ elykdwi@wiraraja.ac.id
}

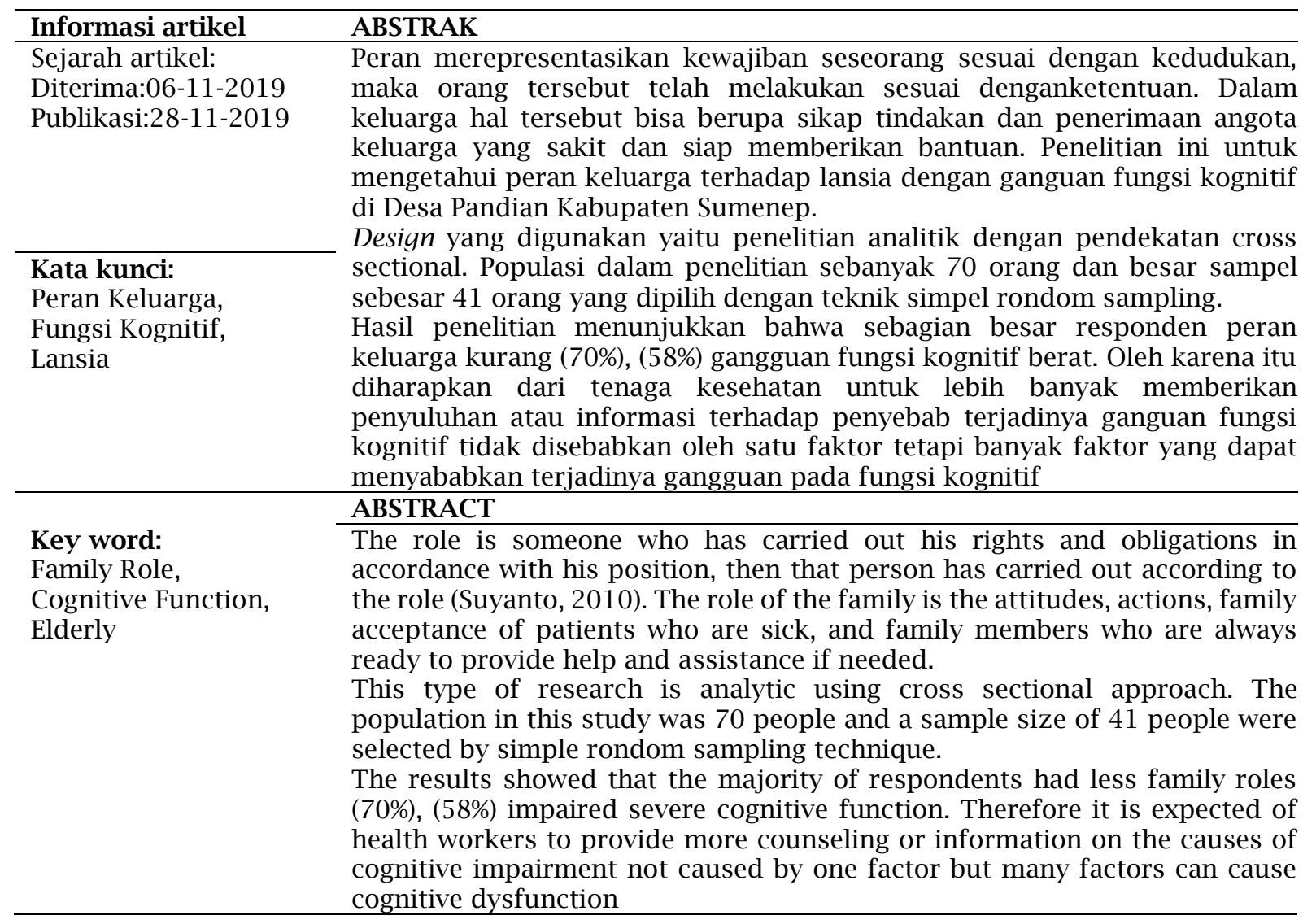

\section{Pendahuluan}

Proses menua dapat dikatakan alur fase terakhir perkembangan pada proses setiap kehidupan manusia. Pada Pasal 1 ayat (2), (3), (4) UU No. 13 Tahun 1998 menerangkan bahwa seseorang yang telah mencapai usia lebih dari 60 tahun bisa dikatakan sebagai usia lanjut (lansia).Penuaan bisa dikatakansebagai proses yang akan dihadapi oleh setiap makhluk hidup, termasuk manusia dan tidak dapat dihindari. Kemudian semakin menua terjadi perubahan pada anatomis, fisiologis, dan biokimia dalam tubuh akan sangat terlihat, sehingga akan berpengaruh terhadap fungsi dan kemampuan keselurruhan. (Depkes RI,2001).
Pertanda menjadi tua yaitu ditandai adanya menurunnya biologis dan melemahnya fisik, diantaranya mengendurnya kulit dan terlihat keriput, rambut memutih (uban), gigi yang semakin lama semakin ompong, pendengaran kurang jelas, penglihatan yang mulai berkurang, gerakan menjadi lambat, serta kondisi fisik mudah lelah. Pertanda lain yang akan terjadi yaitu berkurangnya kemampuan kognitif seperti pikun (pelupa), serta tidak mudah menerima atau mencerna hal/ ide baru.

Di zaman sekarang ini, tidak sedikit anggota keluarga yang tidak ingin mengurus anggota keluarganya yang sudah lansia dikarenakan berbagai macam alasan, 
salah satunya yaitu sibuk bekerja, dan sebagainya. Keluarga tersebut lebih memilih menitipkan anggota keluarganya yang lansia ke panti jompo, atau hanya membiarkannya berdiam diri di dalam rumah. Justru hal inilah yang dapat meningkatkan masalah fungsi kognitif pada lansia tersebut.

Saat ini, jumlah lansia di seluruh dunia diperkiran sekitar 625 juta orang lebih (10\% berusia di atas 60 tahun), dan di tahun 2025 akan mengalami peningkatan yang cukup signifikan (Nugroho,2012). Badan Pusat Statistika menyatakan bahwa pada tahun 2017 jumlah dan proporsi penduduk lansia di Indonesia 23,66 juta orang(9,03\%). Diprediksi jumlah penduduk lansia di tahun 2020 nanti akan bertambah menjadi 27,08 juta orang,di tahun 2025 sebanyak 33,69 juta, di tahun 2030 sebanyak 40,95 juta dan di tahun 2035 sebanyak 48,19 juta (kenmenkes,2017). Pada tahun 2017 jumlah lansia di kabupaten sumenep yaitu dari umur 60-64 tahun sebanyak 56.193 jiwa, 65-69 tahun sebanyak 37.102 jiwa, 70-74 tahun sebanyak 24.065 jiwa, 75 tahun ke atas sebanyak 24.054 jiwa dan jika di total jumlah lansia dari umur 60-75 keatas di kabupaten sumenep sebanyak 141.414 jiwa. Data lansia yang di dapat pada tahun 2018 di Desa Pandian terdapat 70 jiwa. Usia lanjut berjumlah 30 jiwa, sedangkan lanjut usia tua berjumlah 22 jiwa dan usia sangat tua terdapat 18 jiwa.

Kognitif menunjukkan kemampuan otak seseorang dalam mempersepsikan dan kemampuan berhitung, bahasa, informasi, memori, dan pemecahan masalah. Gangguan kognitif jangka panjang mempengaruhi kegiatan sehari-hari. Fungsi kognitif seseorang dipengaruhi adanya permasalahan sistem saraf pusat meliputi kekurangan oksigen di otak, aging, alzeimer dan kekurangan nutrisi. Lansia seringkali menghadapi gangguan fungus kognitif diantaranya gangguan orientasi waktu dan ruang, serta kesulitan menerima hal/ide baru. Jika hal ini tidak ditindak lanjuti, maka akan terjadi gangguan fungsi kognitif bagi lansia. Selain itu juga tidak dapat mengidentifikasi lansia yang berisiko mengalami gangguan fungsi kognitif tersebut.

Berdasarkan hasil studi awal yang dilakukan oleh peneliti di Desa Pandian Kabupaten Sumenep dengan menggunakan MMSE didapatkan 7 dari 10 orang lansia mengalami perubahan mental (ganguan fungsi kognitif) dari 70\% yang mengalami gangguan fungsi kognitif yaitu menurunnya daya ingat. Sehingga mengganggu aktifitas sehari-hari, sedangkan 30\% mengalami gangguan fungsi kognitif dalam kemampuan berfikir salah satunya dalam proses pemecahan masalah.

Peran keluarga terhadap masalah fungsi kognitif yang sering dihadapi lansia di sini sangat penting. Keluarga adalah unit terkecil dari masyarakat dan yang paling mengerti kondisional anggota keluarganya. Selain itu, keluarga memiliki peran utama untuk meminimalisir masalah gangguan mental (kognitif) pada anggota keluarganya yang sudah lansia, serta mempertahankan kesehatannya. Adapun beberapa peranan keluarga yang dapat dilakukan untuk mengurangi masalah kognitif yang dialami lansia, diantaranya menjaga serta merawat lansia, melatih daya tahan mentalnya, menjaga perubahan sosial dan ekonomi, serta terus berikan motivasi.

Berdasarkan permasalahan yang ada tentang gangguan fungsi kognitif pada lansia, maka diadakan penelitian tentang bagaimana peran keluarga terhadap masalah fungsi kognitif yang sering dihadapi oleh lansia di Desa Pandian Kabupaten Sumenep. Oleh karena itu peneliti tertarik mengambil judul tentang "Hubungan Peran Keluarga dengan Fungsi Kognitif pada Lansia Kabupaten Sumenep" untuk mengetahui seberapa besar peran keluarga terhadap gangguan mental (kognitif) pada anggota keluarganya yang sudah lansia.

\section{Metode Penelitian}

Penelitian ini metode penelitian analitik dengan rancang bangun cross sectional (Notoatmojo, 2012). Populasi yaitu semua lansia di Desa Pandian pada tahun 2018 sebanyak 70 orang. Dalam penelitian ini sampelnya adalah sebagian lansia di Desa Pandian tahun 2018 sebanyak 40 orang.Metode dan pengambilan sampel dalam penelitian adalah Simpel Random Sampling yaitu setiap elemen diseleksi secara acak, dengan cara menulis nama dan diambil secara acak. Instrumen menggunakan kuisioner paten dan kuisioner yang sudah dibuat oleh peneliti sebelumnya. Dalam penelitian yang berjudul Hubungan Peran Kluarga dengan Fungsi Kognitif Pada Lansia menggunakan dua kuisioner, yaitu : Mini Mental State Examinition (MMSE) untukvariabael fungsi kognitif dan kuisioner Peran Keluarga.

Mini menta lstate Examination (MMSE) menilai secara klinis sebuah fungsi kognitif 
yang terdistribusi dan terlokasi (Suryono, 2015). MMSE terditi dari 30 pertanyaan, terbagi menjadi 11 item pertanyaan dan perintah, yang meliputi rincian intelegensi, perhatian, fungsi eksekutif, memori, bahasa, dan visuospasial (Suryono, 2015).

Kuisioner yang digunakan untuk variabel peran keluarga merupakan kuisioner yang sudah dibuat oleh peneliti sebelumnya. Kuisioner ini digunakan untuk melihat perilaku atau kebiasaan individu, apakah masuk dalam kategori baik, cukup atau kurang. Kuisioner peran keluarga terdapat 12 pertanyaan dimana jika responden menjawab tidak penah pada pertanyaan nilainya 0 , jika menjawab kadang - kadang maka nilainya 1, jika menjawab sering maka nilainya 2, dan jika menjawab selalu maka nilainya 3. Dan kuisioner ini menggunakan skala likert yang artinya terdapat empat jawaban yaitu tidak pernah, kadang-kadang, selalu, dan sering. Kuisioner ini juga sebagai penguat data yang sudah ada menjadi lebih valid dan dapat dipertanggung jawabkan.

Data hasil penelitian dianalisis secara distributive dan inferensial. Analisis distibutif dibuat dalam bentuk table dan narasi. Analisis inferensial menggunakan uji Spearman. Uji hipotesis dilakukan dengan membedakan bila $p$ value (sig) $\leq$ 0,05, H0 ditolak, berarti ada hubungan peran keluarga dengan fungsi kognitif pada lansia di Desa Pandian Kabupaten Sumenep dan bila $p$ value (sig) $>0,05, \mathrm{H} 0$ diterima, berarti tidak ada hubungan peran keluarga dengan fungsi kognitif pada lansia di Desa Pandian Kabupaten Sumenep.

\section{Hasil Penelitian \\ Data Umum}

Data yang terkumpul dari responden akan disajika tentang karakteristik responden yang meliputi jenis kelamin, umur, pendidikan dan pekerjaan.

\section{a. Jenis Kelamin}

Tabel 1 Karakteristik lansia berdasarkan jenis kelamin di Desa Pandian Kabupaten Sumenep tahun 2019.

\begin{tabular}{ccc}
\hline Jenis kelamin & $\mathrm{F}$ & $\%$ \\
\hline Laki-laki & 10 & 24,4 \\
\hline Perempuan & 31 & 75,6 \\
\hline Total & 41 & 100,0
\end{tabular}

Sumber: Data primer , 2019
Tabel 1 menunjukkan bahwa sebagian besar lansia berjenis kelamin perempuan, yaitu sebanyak 31 responden $(75,6 \%)$.

\section{b. Umur}

Tabel 2 Karakteristik lansia berdasarkan umur di Desa Pandian Kabupaten Sumenep tahun 2019

\begin{tabular}{ccc}
\hline Umur & f & $\%$ \\
\hline 60-69 tahun & 26 & 63,4 \\
\hline 70-79 tahun & 15 & 36,6 \\
\hline Total & 41 & 100,0 \\
\hline
\end{tabular}

Sumber : Data primer , 2019

Tabel 2 menunjukkan bahwa sebagian besar lansia berumur 60-69 tahun, yaitu sebanyak 26 responden $(63,4 \%)$.

c. Karakterisitik Lansia Berdasarkan Pendidikan

Tabel 3 Karakteristik lansia berdasarkan jenis kelamin di Desa Pandian Kabupaten Sumenep tahun 2019.

\begin{tabular}{ccc}
\hline Pendidikan & $\mathrm{f}$ & $\%$ \\
\hline Tidak sekolah & 7 & 17,1 \\
\hline SD & 20 & 48,8 \\
\hline SMP & 7 & 17,1 \\
\hline SMA & 5 & 12,2 \\
\hline S1 & 2 & 4,9 \\
\hline Total & 41 & 100,0 \\
\hline
\end{tabular}

Sumber : Data primer , 2019

Tabel 3 menunjukkan bahwa sebagian besar lansia berpendidikan SD sebanyak 20 orang $(48,8 \%)$.

d. Pekerjaan

Tabel 4 Karakteristik lansia berdasarkan pekerjaan di Desa Pandian Kabupaten Sumenep tahun 2019.

\begin{tabular}{ccc}
\hline Pekerjaan & $\mathrm{f}$ & $\%$ \\
\hline IRT & 20 & 48,8 \\
\hline Swasta & 9 & 22,0 \\
\hline Pedagang & 9 & 22,0 \\
\hline Pensiunan & 3 & 7,3 \\
\hline Total & 41 & 100,0 \\
\hline
\end{tabular}

Sumber : Data primer , 2019

Tabel 4 menunjukkan bahwa hampir setengahnya lansia bekerja IRT (Ibu Rumah Tangga) sebanyak 20 orang $(48,8 \%)$

\section{Data Khusus}

Pada data khusus akan disajikan hasil pengolahan data yang meliputi distribusi frekuensi responden berdasarkan variabel yang diteliti. 
1. Peran Keluarga

Tabel 5 Distribusi frekuensi lansia berdasarkan peeran keluarga pada lansia di Desa Pandian Kabupaten Sumenep tahun 2019.

\begin{tabular}{ccc}
\hline Peran Keluarga & F & $\%$ \\
\hline Baik & 2 & 4,9 \\
\hline Cukup & 10 & 24,4 \\
\hline Kurang & 29 & 70,7 \\
\hline Total & 41 & 100,0 \\
\hline
\end{tabular}

Sumber : Data primer , 2019

Berdasarkan pada tabel 5 di atas menunjukkan sebagian besar peran keluarga pada lansia di Desa Pandian adalah kurang, yaitu sebanyak 29 lansia (70,7\%).

\section{Fungsi Kognitif}

Tabel 6 Distribusi frekuensi lansia berdasarkan fungsi kognitif pada lansia di Desa Pandian Kabupaten Sumenep tahun 2019.

Tabel 7 Distribusi frekuensi lansia berdasarkan hubungan peran keluarga dengan fungsi kognitif pada lansia di Desa Pandian Kabupaten Sumenep tahun 2019.

\begin{tabular}{ccccccccc}
\hline & \multicolumn{4}{c}{ Fungsi Kognitif pada Lansia } & \multicolumn{2}{c}{ Total } \\
\cline { 2 - 9 } Peran keluarga & $\begin{array}{c}\text { Tidak Ada } \\
\text { Kelainan Kognitif }\end{array}$ & $\begin{array}{c}\text { Kelainan } \\
\text { Kognitif Ringan }\end{array}$ & $\begin{array}{c}\text { Kelainan } \\
\text { Kognitif Berat }\end{array}$ & \\
\cline { 2 - 9 } & $\mathrm{F}$ & $\%$ & $\mathrm{~F}$ & $\%$ & $\mathrm{~F}$ & $\%$ & $\mathrm{~F}$ & $\%$ \\
\hline Baik & 2 & $\begin{array}{c}10 \\
0\end{array}$ & 0 & 0,0 & 0 & 0,0 & 2 & $\begin{array}{c}10 \\
0\end{array}$ \\
\hline Cukup & 2 & 20 & 8 & 80,0 & 0 & 0,0 & 10 & $\begin{array}{c}10 \\
0\end{array}$ \\
\hline Kurang & 0 & 0,0 & 5 & 17,2 & 24 & 82,8 & 29 & $\begin{array}{c}10 \\
0\end{array}$ \\
\hline Total & 4 & 9,8 & 13 & 31,7 & 24 & 58,5 & 41 & $\begin{array}{c}10 \\
0\end{array}$ \\
\hline
\end{tabular}

Uji Spearman: Correlation is significant at the 0,01 level (2-tailed).

Berdasarkan tabel 7 di atas menunjukkan bahwa peran keluarga baik sebanyak 2 lansia (100\%), yaitu dengan tidak ada kelainan kognitif sebanyak 2 lansia (100\%). Peran keluarga cukup sebanyak 10 lansia (100\%), yaitu 2 (20\%) lansia tidak ada kelainan kognitif dan 8 lansia (80\%) kelainan kognitif ringan. Peran keluarga kurang sebanyak 29 lansia (100\%), yaitu 5 lansia $(17,2 \%)$ kelainan kognitif ringan dan 24 lansia $(82,8 \%)$ kelainan kognitif berat.

Setelah dilakukan analisis tentang hubungan peran keluarga dengan fungsi kognitif pada lansia dengan menggunakan uji analisi statistik kolerasi spearman's didapatkan hasil yang significan yaitu $p$ value $=0.01(p<a=0.05)$ maka dapat disimpulkan hasil di atas bahwa Ho ditolak karena nilai dan $\mathrm{H}_{1}$ diterima artinya

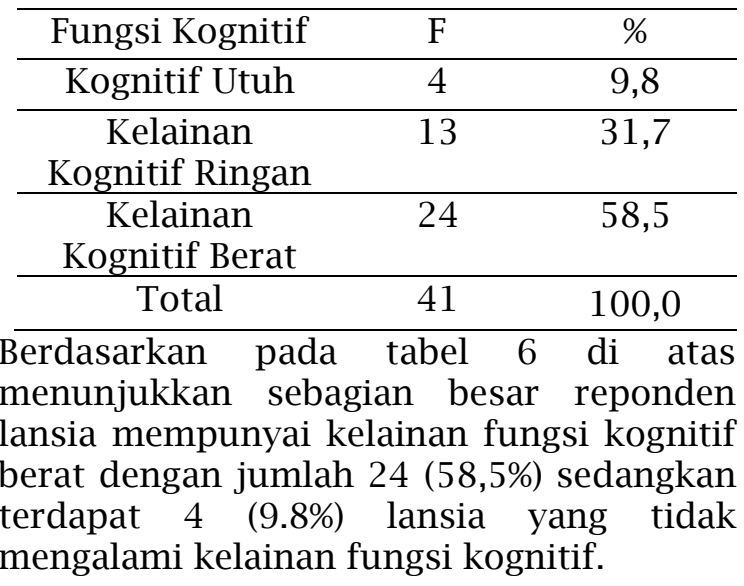

3. Hubungan Peran Keluarga Dengan Fungsi Kognitif Pada Lansia

Untuk mengetahui ada hubungan atau tidaknya antara variabel independen dan dependen yaitu Hubungan Peran Keluarga Dengan Fungsi Kognitif Pada Lansia maka dilakukan penghitungan dengan komputer terhadap masing-masing variabel menggunakan uji statistik.

Berdasarkan pada tabel 6 di atas menunjukkan sebagian besar mempunyai kelainan fungsi kognitif terdapat 4 (9.8\%) lansia yang tidak . 
Friedman (1998), menyebutkan bahwa ikatan kekeluargaan memberikan dukungan pada lansia dalam proses pemecahan masalah. Keluarga juga mempunyai peranan dalam meningkatkan kemampuan interpersonal dan social lansia sehingga kegiatan yang biassa dilakukan ini akan bermanfaat untuk lansia baik fisik maupun psikis.

Apabila pemenuhan kebutuhan perawatan tersebut dapat terpenuhi, rasa percaya diri seseorang akan meningkat (Hidayat, 2009). Peran keluarga yang merupakan seperangkat perilaku antar pribadi dalam keluarga memberikan dampak yang positif terhadap kualitas hidup lansia dan memberikan dampak yang signifikan pada lansia dalam memenuhi kebutuhan sehari hari mencakup bio, psiko sosio dan kulturalnya (Setiadi, 2008).

\section{Gambaran Fungsi Kognitif}

Seperti dijelaskan dalam tabel 5.6 tentang prevalensi pada fungsi kognitif pada lansia di Desa Pandian Kabupaten Sumenep dengan jumlah sampel 41 dari 70 populasi responden lansia bahwa sebagian besar reponden lansia mempunyai kelainan fungsi kognitif berat dengan jumlah 24 $(58,5 \%)$ responden sedangkan responden lansia yang termasuk dalam kategori kelainan kognitif ringan berjumlah 13 (31.7 \%) dan terdapat $4(9,8 \%)$ responden lansia yang tidak mengalami kelainan fungsi kognitif.

Kognitif lansia adalah kemampuan pada lansia yang terkait dengan kecerdasan meliputi ingatan jangka panjang, keinginan belajar, mampumemahami, mampu mengatasi sebuah permasalahan dan memberikan motivasi. Mini Mental State Examination (MMSE) digunakan untuk mengukur tingkat kognitif yang dapat menunjukkan status mental seeorang sekaligus menunjukkan apakah ada penyakit neurodegeneratif (Agustiana, 2014).

Penurunan fungsi sistem saraf pada seseorang akan memberikan dampak pada fungsi kognitif. Hal tersebut menunjukkan bahwa fungsi kognitif akan menurun jika terjadi gangguan pada sistem saraf pusat. Lansia yang mengalami proses degeratif akan mengalami penuruan kemampuan sistem saraf pusat dan akan menyebabkan penurunan kemampuan fungsi kognitif ringan atau berat. Faktor lain yang menjadi penyebab menurunnya fungsi kognitif adalah jenis kelamin, usia, hereditas, lingkungan, dan penyakit penyerta khususnya yang merusak sistem saraf (Bandiyah 2009).

Tindakan dalam uapya peningkatan fungsi kognitif pada diantaranya dengan melibatkan lansia sevara aktif dalam kegiatan sehari-hari diantaranya mencatatkalender atau buku catatan, beribadah, melakukan senam lansia dan menganjurkan lansia untuk melakukan kegiatan yang menyenangkan baginya, sehingga otak dapat berfikir dan berkreasi gengan sering berpikir lansia dapat meningkatkan fungsi kognitifnya.

Berdasarkan hasil penelitian sebagian lansia termasuk dalam kategori kelainan kognitif berat. Hal ini terjadi karena dilihat dari karakteristik lansia Di Desa Pandian bahwa 50\% lansia tingkat pendidikannya yaitu tidak tamat SD dimana tingkat pendidikan sangat berpengaruh terhadap kemampuan fungsi kognitif seperti daya ingat (memori), kemampuan dalam belajar, aspek intelektual dan aspek bahasa contohnya banyak lansia di Desa Pandian tidak bisa menjawab orientasi mengenai musim, orientasi negara, provinsi dan tidak bisa menulis.

\section{Hubungan Peran Keluarga dengan Fungsi Kognitif}

Setelah dilakukan analisis penelitian tentang hubungan peran keluarga dengan fungsi kognitif pada lansia menggunakan uji statistik kolerasi spearman's didaptkan hasil yang significan yaitu $p$ value $=0,01$ ( $p$ $<\mathrm{a}=0,05)$ maka dapat disimpulkan bahwa $\mathrm{H}_{0}$ ditolak dan $\mathrm{H} 1$ diterima yang berarti ada hubungan peran keluarga dengan fungsi kognitif pada lansia di Desa Pandian Kabupaten Sumenep.

Tabel 5.7 menunjukkan bahwa peran keluarga baik sebanyak 2 responden (100\%), yaitu dengan tidak ada kelainan kognitif sebanyak 2 responden (100\%). Peran keluarga cukup sebanyak 10 responden (100\%), yaitu 2 (20\%) responden tidak ada kelainan kognitif dan 8 responden (80\%) kelainan kognitif ringan. Peran keluarga kurang sebanyak 29 responden (100\%), yaitu 5 responden $(17,2 \%)$ kelainan kognitif ringan dan 24 responden $(82,8 \%)$ kelainan kognitif berat.

Keluarga menjadi penyambung berbagai usaha kesehatan masyarakat dengan upaya yang dilakukan oleh perawat.Keluarga tidak hanya berdasarkan jumlah tetapi kesatuan yang unik dalam menghadapi masalah. Kultur di Indonesia 
masih sangat kental tentang bentuk penghargaan kepada orang tua, berbakti kepada orang tua dapat diwujudkan dengan memberikan bantuan kepada lansia demi tetap optimalnya kualitas hidup lansia. Kegiatan tersebut merupakan salah satu bentuk peran keluarga dalam memberikan dukungan kepada lansia, sehingga dapat memberikan harapan fungsi kognitif lansia tidak mengalami penuruan yang berat seiring dengan penambahan jumlah usia dan penurunan fungsi sistem saraf pusat. Peran keluarga telah terbukti sebagai faktor pelindung yang baik dalam menjaga fungsi kognitif lansia. Peran keluarga dapat berupa material maupun non material.

\section{KESIMPULAN DAN SARAN}

\section{Kesimpulan}

Berdasarkan hasil penelitian tentang Hubangan Peran Keluarga Dengan Fungsi Kognitif Lansia Di Desa Pandian Kabupaten Sumenep sebagai berikut:

1. Sebagian besar peran keluarga lansia di Desa Pandian termasuk dalam kategori kurang baik.

2. Sebagian besar lansia di Desa Pandian Kabupaten Sumenep mengalami kelainan kognitif berat.

3. Ada hubungan antara peran keluarga dengan fungsi kognitif pada lansia di Desa Pandian Kabupaten Sumenep

\section{Saran}

1. Bagi Instansi Kesehatan

Diharapkan penelitian ini dapat dijadikan sebagai masukan dalam menentukan standar penanganan yang efektif dan tepat bagi lansia.

2. Bagi Institusi Pendidikan Keperawatan Kepada pihak isntitusi pendidikan keperawatan diharapkan dapat menambah wawasan mahasiswa dalam menambah informasi tentang fungsi kognitif pada lansia dan faktor yang mempengaruhinya.

3. Bagi masyarakat

Kepada pihak masyarakat untuk melakukan pembinaan keluarga dalam pelaksanaan peran kepada anggota keluarga yang lanjut usia agar terhindar dari depresi

\section{DAFTAR PUSTAKA}

Bagong, Suyanto. 2010. Metode Penelitian Sosial. Jakarta: Prenada Media Group.

Behrman, R. E., Kliegman, R. M., \& Arvin, A. M. 2000. Ilmu Kesehatan Anak
Nelson. Penerjemah: A. Samik Wahab. Volume 1. Edisi 15.Jakarta: Penerbit Buku Kedokteran EGC.

Departemen Kesehatan RI. 1998. Proyek Peningkatan Pelayanan Puskesmas, Modul A-E, Pengembangan Program Jaminan Mutu Pelayanan Kesehatan Dasar.

Departemen Kesehatan RI. 2001. Pedoman Pembinaan Kesehatan Usia Lanjut Bagi Petugas Kesehatan. Jakarta: Direktorat Bina Kesehatan Keluarga.

Departemen Kesehatan RI. 2003. Pedoman Pengelolahan: Kegiatan Kesehatan di Kelompok Usia Lanjut. Edisi Ke-2. Jakarta.

Friedman, M. 1998. Keperawatan Keluarga: Teori dan Praktek. Diterjemahkan oleh Ina Debora dan Yoakim. Jakarta: EGC.

Ginsberg L., 2008. Lecture Notes Neurology. Jakarta: Erlangga.

Hanifa, Azmi. 2016. Hubungan Kualitas Tidur Dan Fungsi Kognitif Pada Lanjut Usia di Panti Sosial Margaguna Jakarta Selatan. Skripsi. Jakarta. Fakultas Kedokteran dan Ilmu Kesehatan Universitas Islam Negeri Syarif Hidayatullah.

Hawari, D. 2007. Pendekatan Holistik Pada Gangguan Jiwa. Jakarta: Balai Penerbit FKUI.

Hernata, I., 2013. Ilmu Kedokteran Lengkap tentang Neurosains. Yogyakarta: XD- Medika. Pp 114-115.

Hidayat, A. A. 2007. Metode Penelitian Keperawatan dan Teknik Analisis Data. Jakarta: Salemba Medika

Hidayat, S. (2014). Dzikir Khafi untuk Menurunkan Skala Nyeri Osteoartritis Pada Lansia. Jurnal Ilmu Kesehatan, 1(1), 13-22. https://doi.org/https://doi.org/10.24 929/jik.v1il.119

Hidayat, S. dan E. D. M. (2018). Terapi Kombinasi Sugesti Dan Dzikir Dalam Peningkatan Kualitas Tidur Pasien. Care: Jurnal Ilmiah Ilmu Kesehatan, 6(3), 219-230. Retrieved from https://jurnal.unitri.ac.id/index.php/ care/article/view/953

Hidayat, Syaifurrahman, Mujib Hannan, L. H. dan U. R. (2018). Klenengan Music Therapy on Sleep Quality in Elderly Patients at Pratama. Journal of Medical Science and Clinical Research, 6(12), 107-112. https://doi.org/https://dx.doi.org/10 
$.18535 / \mathrm{jmscr} / \mathrm{v} 6 \mathrm{i} 12.16$

Maryam, R Siti, Mia Fatma Ekasari, Rosidawati, Ahmad Jubaedi, dan Irwan Batubara.2008. Mengenal Usia Lanjut dan Perawatannya. Jakarta: Salemba Medika.

Meiner, Sue E., dan Annette G. Lueckenotte. 2006. Gerontologic Nursing (3th ed.). Philadelphia: Mosby Elsevier

Mubarak, Wahit Iqbal. Nurul Chayatin dan Bambang Adi Santoso. 2009. Ilmu Keperawatan Komunitas Konsep dan Aplikasi. Jakarta: Salemba Medika.

Muttaqin,Arif. 2008. Buku Ajar Asuhan Keperawatan Klien Dengan Gangguan Sistem Imunologi. Jakarta: Salemba Medika

Notoatmodjo, S. 2007. Promosi Kesehatan dan Ilmu Perilaku. Jakarta : Rineka Cipta

Notoatmojo. 2012. Metodologi Penelitian Kesehatan. Jakarta: Rineka Cipta.

Nugroho, W. 2000. Keperawatan Gerontik. Edisi Ke-2. Jakarta: EGC.

Nugroho, W.H. 2012. Keperawatan Gerontik \& Geriatrik. Edisi Ke-3. Jakarta: EGC

Nursalam. 2014. Metodelogi Penelitian Ilmu Keperawatan. Jakarta: Salemba Medika.

Nursalam. 2016. Metodologi Penelitian Ilmu Keperawatan: Pendekatan Praktis. Medika

Edisi 4. Jakarta: Salemba

Padila. 2012. Keperawatan Keluarga.

Yogyakarta: Nuha Medika. 